\title{
Exploration of Customer Complaint Behaviors Toward Macau Low-cost Carriers
}

\author{
Yang $\mathrm{Li}^{1}$, Grace Suk Ha Chan ${ }^{2}$, Irini Lai Fun Tang ${ }^{2}$ \\ ${ }^{1}$ Faculty of International Tourism and Management, City University of Macau, Macau, SAR, China \\ ${ }^{2}$ Assistant Professor, Faculty of International Tourism and Management, City University of Macau, Macau, SAR, \\ China \\ Correspondence: Suk Ha Grace Chan, Faculty of International Tourism and Management, City University of \\ Macau, Macau SAR, China.
}

Received: July 6, 2017

doi:10.5539/ibr.v10n9p73
Accepted: August 1, 2017

Online Published: August 14, 2017

URL: https://doi.org/10.5539/ibr.v10n9p73

\begin{abstract}
In 2015, the number of complaints against airlines in Macau increased considerably. In today's keen competitive business environment, maintaining a good reputation and positive word-of-mouth within the industry is essential to increase competitiveness. Hence, Macau low-cost carriers should gather more customer feedback to improve their product and service quality. Macau passengers would speak to the management, their friends and family, and media and even choose boycott the companies when they feel dissatisfied with their travel experiences. The present study aimed to investigate the behavior of passengers in Macau toward low-cost carriers. A qualitative approach was adopted using a sample of 20 respondents who had pre viously submitted complaints to low-cost carriers. Semi-structured questions were asked in the in-depth interview. The results demonstrated the rationale behind the complaints. Perception of complaint behavior of Macau low-cost carriers' passengers was discovered. Recommendations were proposed to provide insights for industrial practitioners.
\end{abstract}

Keywords: complaint behavior, airline passengers, Macau low-cost carriers, service quality

\section{Introduction}

The annual increase in complaints has caused the Macao airline industry to experience a severe service crisis. The keen competition in the hospitality industry makes understanding and satisfying guests critical for businesses. However, customer complaints are also an important part of the hospitality industry, especially the aviation industry. Air travel demand is closely associated with the economic status of a country. According to Chen (2008), providing passengers with high quality service is a core competitive advantage for an airline's profitability and sustained de velopment in highly competitive circumstances. In the airline industry, Chang, Chen and Chang (2008) suggested that airlines face a very specific problem that could influence the satisfaction of customers, namely, airlines offer multiple opportunities for mistakes to occur during service de livery and are therefore particularly prone to service failures. In order to attract more passengers and get their good word-of-mouth, handling customer complaints properly can increase customer loyalty. Understanding how passengers evaluate the integrated service process and identifying the critical primary and sub-dimensions used to measure integrated service quality are important. So it is very important to explore customer complaint behaviors.

According to statistics from the Civil Aviation Authority of Macau (CAAM), 73 complaints were received in 2015, indicating an increase of $43 \%$ from the figure in 2014. However, 66 complaints against the airlines accounted for $87 \%$ of the complaints received in 2015 (CAAM, 2015). Does the decreased number of complaints reflect an improvement in the overall service quality of Macau's airline industry?

Under keen competition among the 28 airline carriers in the Macau aviation industry (Macau Airport, 2016), maintaining a good reputation and positive word-of-mouth is essential to increase competitiveness. Therefore, the present study can provide significant help to industry practitioners in improving complaint handling and service recovery to retain customer loyalty. 
Table 1. Complaints Against the Macau Airline Industry (2001-2015)

\begin{tabular}{|c|c|c|c|c|c|c|c|c|c|c|c|c|c|}
\hline \multicolumn{6}{|c|}{ Local Airlines } & \multicolumn{6}{|c|}{ Foreign Airlines } & \multicolumn{2}{|c|}{ Others (non-aviation } \\
\hline Staff & $\begin{array}{l}\text { Services / } \\
\text { Facilities / } \\
\text { Operation }\end{array}$ & $\begin{array}{c}\text { Denied } \\
\text { boarding }\end{array}$ & \begin{tabular}{|l|} 
Flight Delay / \\
Cancellation / \\
Assistance and \\
Compensation
\end{tabular} & $\begin{array}{c}\text { Aviation } \\
\text { Safety }\end{array}$ & $\begin{array}{c}\text { Lost / } \\
\text { Damaged } \\
\text { of Articles }\end{array}$ & Staff & \begin{tabular}{|c|} 
Services / \\
Facilities / \\
Operations
\end{tabular} & $\begin{array}{c}\text { Denied } \\
\text { boarding }\end{array}$ & \begin{tabular}{|l|} 
Flight Delay / \\
Cancellation / \\
Assistance and \\
Compensation
\end{tabular} & $\begin{array}{c}\text { Aviation } \\
\text { Safety }\end{array}$ & $\begin{array}{c}\text { Lost / } \\
\text { Damaged } \\
\text { of Articles }\end{array}$ & \begin{tabular}{|c|} 
Facilities / \\
Services \\
surroundin \\
g Airport
\end{tabular} & Immigration \\
\hline 0 & 0 & 0 & 0 & 0 & 0 & 0 & 0 & 0 & 1 & 0 & 0 & 0 & 0 \\
\hline 0 & 1 & 0 & 0 & 0 & 0 & 0 & 0 & 0 & 0 & 0 & 0 & 0 & 0 \\
\hline 0 & 0 & 0 & 2 & 0 & 0 & 0 & 0 & 0 & 0 & 0 & 0 & 1 & 1 \\
\hline 1 & 3 & 0 & 1 & 1 & 0 & 0 & 1 & 0 & 0 & 0 & 0 & 0 & 0 \\
\hline 0 & 2 & 0 & 1 & 1 & 0 & 0 & 2 & 0 & 0 & 1 & 0 & 0 & 1 \\
\hline 0 & 1 & 0 & 1 & 0 & 1 & 2 & 4 & 2 & 0 & 0 & 1 & 0 & 0 \\
\hline 1 & 4 & 0 & 5 & 0 & 1 & 2 & 4 & 0 & 2 & 0 & 1 & 1 & 0 \\
\hline 1 & 7 & 1 & 13 & 0 & 0 & 0 & 4 & 0 & 4 & 0 & 1 & 1 & 1 \\
\hline 2 & 8 & 1 & 17 & 0 & 0 & 0 & 4 & 3 & 4 & 0 & 1 & 1 & 1 \\
\hline 1 & 7 & 3 & 9 & 0 & 0 & 4 & 2 & 2 & 6 & 1 & 2 & 0 & 0 \\
\hline 2 & 6 & 0 & 13 & 1 & 0 & 0 & 5 & 1 & 7 & 1 & 0 & 0 & 0 \\
\hline 0 & 1 & 1 & 7 & 0 & 0 & 0 & 2 & 2 & 5 & 2 & 2 & 0 & 0 \\
\hline 1 & 3 & 0 & 12 & 0 & 0 & 1 & 9 & 6 & 8 & 0 & 1 & 0 & 0 \\
\hline 4 & 9 & 2 & 7 & 0 & 0 & 2 & 9 & 5 & 5 & 0 & 0 & 1 & 0 \\
\hline 3 & 15 & 3 & 8 & 1 & 0 & 2 & 26 & 2 & 5 & 0 & 1 & 0 & 0 \\
\hline 16 & 67 & 11 & 96 & 4 & 2 & 13 & 72 & 23 & 47 & 5 & 10 & 5 & 4 \\
\hline
\end{tabular}

Source: Civil Aviation Authority of Macau, 2016

Previous scholars have identified customer behavior in the other countries. However, few studies have focused on customer behavior in Macau hospitality industry. No research has focused on customer behavior in the Macau airline industry. Several studies have identified complaint behavior in the airline industry, particularly low-cost airlines. Therefore, the present study attempted to fill the gaps in studies on customer complaint behavior toward Macau low-cost carriers. Therefore, this research has the following objectives:

Objective 1: To examine customers' perception toward complaint behavior in the service industry

Objective 2: To investigate customers' complaint behavior against low-cost carriers.

Objective 3: To formulate recommendations to aid managers of low-cost carriers in devising policies to improve complaint handling and service recovery.

\section{Literature Overview}

\subsection{Low-cost and Full-service Carriers}

Low-cost carriers have reshaped the competitive environment within liberalized markets and have made significant impact in the world's domestic passenger markets, which were previously controlled largely by full service network carriers. Figure1 provides a summary of the main differentiating characteristics between the present network carriers and no-frills scheduled airlines. The European and American governments liberalized air rights and imposed deregulation, allowing airlines to choose whichever market they want to serve within the USA or the E.U. A number of low-cost airlines operate routes that originate or end at a major airport, but will only do so if the route will be profitable. If the route turns out to be unprofitable, the low-cost carrier ceases service to the market in question. Low-cost carriers attract passengers from full-service carriers, and thus offer competition, causing reduction in the load factor and profits of full-service carriers. Full-service carriers cannot easily withdraw from a market even if the market is not very profitable, because withdrawing will affect the entire network. A full-service carrier's link between a hub airport and spoke airport serves many different (indirect) markets. If the route is closed because the load factor decreased due to competition on the market between the hub and spoke airports and passengers, then, profit in all other markets within the network will also be lost (Pels, 2008). 


\begin{tabular}{lll}
\hline Product features & Low cost carrier & Full service carrier \\
\hline Brand & One brand: low fare & Brand extensions: fare + service \\
Fares & Simplified: fare structure & Complex fare: structure+ yield mgt \\
Distribution & Online and direct booking & Online, direct, travel agent \\
Check-in & Ticketless & Ticketless, IATA ticket contract \\
Airports & Secondary (mostly) & Primary \\
Connections & Point-to-point & Interlining, code share, global alliances \\
Class segmentation & One class (high density) & Two class (dilution of seating capacity) \\
Inflight & Pay for amenities & Complementary extras \\
Aircraft utilisation & Very high & Medium to high: union contracts \\
Turnaround time & 25min turnarounds & Low turnaround: congestion/labour \\
Product & One product: low fare & Multiple integrated products \\
Ancillary revenue & Advertising, on-board sales & Focus on the primary product \\
Aircraft & Single type: commonality & Multiple types: scheduling complexities \\
Seating & Small pitch, no assignment & Generous pitch, offers seat assignment \\
Customer service & Generally under performs & Full service, offers reliability \\
Operational activities & Focus on core (flying) & Extensions: e.g., maintenance, cargo \\
\hline
\end{tabular}

Figure 1. Product features of low-cost and full-service carriers

\section{Source: O'Connell \& Williams, 2005}

\subsection{Customer Complaint Behavior in the Airline Industry}

Airlines are an important service industry and interaction among service providers and seekers increases the chances of failure at each step of the service delivery process. Gupta and Sharma (2015) examined the effect of demographic variables on consumer complaint intent. Service failures are unpreventable in core service sectors such as the airline industry. The reason for these failures can be the service delivery system, employee response to customer needs and requests, and unprompted and unsolicited employee actions (Bitner, Booms \&Tetreault, 1990). Chang, Chen and Chang (2008) suggested that airlines face a very specific problem that could influence the satisfaction of customers, namely, airlines offer multiple opportunities for mistakes to occur during service delivery and are therefore particularly prone to service failures. A number of internal mistakes or external disruptions could cause customers to experience service failure.

\subsection{Customer Complaint Behavior}

The study of customer complaint behavior began in the 1970s, influenced mainly by Western consumer supremacy, and has been the focus of international academic circles of service management (Day \& London, 1977; Jacoby\&Jaccard, 1981). Motivations of customer complaints are mainly dissatisfaction, clarification of problems and responsibilities, maintenance of rights and apologies, and a degree of compensation from service providers. Depending on the motive of the customer, Day (1981) divides customer complaint into three categories: (1) seeking compensation, that is, the customer directly or indirectly demands a specific compensation from the seller, (2) emotional and not for compensation, such as to persuade family and friends not to buy, and (3) individual boycott, that is, refusing to buy a brand of products.

Singh (1988) also divides complaints into three categories: voice, third party, and private customer complaint behaviors, according to the object of complaint.

Singh (1990) focuses on dissatisfied customers and proposed behaviors such as complaints, leaving negative word-of-mouth into three variables:(1) complaints on the likelihood of success; (2) the value of complaints, that is, customers complain about the cost and benefits; and (3) personal factors (product knowledge, consumer rights, quality and satisfaction regarding the degree of awareness, and complaint pipeline).

\subsection{Proposed Factor Structure for Airline Services}

Service quality is an overall concept consisting of four primary dimensions regarding quality: interaction, physical environment, outcome, and access. The four primary dimensions are consistent with previous research (Brady \& Cronin, 2001; Chen, Lee, Chen, \& Huang, 2011; Rust \& Oliver, 1994). Each primary dimension has its own sub-dimensions. Following Brady and Cronin (2001), the sub-dimensions are as follows. For interaction quality: conduct, expertise, and problem-solving. For physical environment quality: cleanliness, comfort, tangibles, and safety and security; for outcome quality: valence and waiting time. For access quality: information and convenience. The first dimension, interaction quality, is referred to as the interpersonal interface between service providers and customers which take place during service delivery (Brady \& Cronin, 2001). The second primary dimensions of service, namely, physical environment quality, has been investigated since the beginning of the 1970s (Kotler, 1973) for its environmental influence on customer behavior. Elliott, Hall, and Stiles (1992) refer to physical environment quality as the physical features of the service production process. The third 
primary dimension, outcome quality, focuses on the outcome of the service and indicates what customers gain from the service; in other words, whether outcome quality satisfies customers' needs and wants (McDougall \& Levesque, 1994; Rust \& Oliver, 1994). The last primary dimension, access quality, refers to the ease and speed with which people reach their desired locations (Shonk \& Chelladurai, 2008). Parasuraman et al. (1985) indicate that access quality is one of the most important attributes of service quality.

\subsection{Performance, Fairness, and Response Theories}

\subsubsection{Performance Theories}

The treatment of the topic will be succinct because the disconfirmation paradigm has recently been discussed in detail (Oliver \& DeSarbo, 1988; Tse \& Wilton, 1988), According to this paradigm, satisfaction is an outcome of a process consisting of the following steps. Prior to an exchange, consumers hold attribute norms or form attribute performance expectations. As the product is used or service is rendered, the consumer compares their perceptions of performance to these standards. Performance above the standard has been termed positive disconfirmation, while performance below is referred to as negative disconfirmation. The degree of incremental (dis)satisfaction is a direct function of positive (negative) disconfirmation.

\subsubsection{Fairness Theory}

Previous studies have used justice theories to explain the connection between feelings of dissatisfaction and customers' decisions to complain (Harris, Thomas, \& Williams 2013). In the context of the model, equity theory works well because a cost-benefit calculation (ratio of outcomes to inputs) is included to explain consumer dissatisfaction resulting from service failures or poor quality. Hence, even if the customer's complaint is successful and results in a full refund, for example, inequity could result in the effort required to lodge the complaint outweighing the benefit from its resolution. What's more, the effort needed to involve official third parties produces inequity because despite the effort being successful, the customer had to exert a significant amount of additional effort to complain to the third party, and often the third party, not the company, gets credit for resolving the problem (Cronin \& Fox 2010).

Tax et al. (1998, p. 62) proposed a three dimensional concept of justice: distributive (dealing with decision outcomes), procedural (dealing with decision-making procedures) and interactional (dealing with interpersonal behavior in the enactment of procedure and delivery of outcomes). Justice theory provides a comprehensive framework for understanding the complaint process (Tax \& Brown, 1998). Paying attention to consider the three dimensions involved is very important to avoid focusing exclusively on one dimension. Acommon agreement on which dimension of justice has the largest impact on consumers does not exist (Blodgett, Hill \& Tax, 1997, p. 198-199; Kau \& Loh, 2006, p. 107).

\subsubsection{Response Theory}

The study of consumer complaints is particularly focused on alternative choices for dissatisfied customers, and emphasizes that public complaints are an alternative to less frequent use, which has an adverse effect on all subjects. On the contrary, "an increase in the rates at which consumers voice complaints could benefit individual consumers, businesses and society as a whole" (Best \& Andreasen, 1977, p. 730). Less attention has been gi ven to real complaints, mechanisms involved and organizational response (Resnik, Gnauck \&Aldrich, 1977; Gilly, 1987; Hsieh, Thomas \& Rotem, 2005, p. 309). Dissatisfied consumers who do not complain and complainers who do not receive a satisfactory redress determine what is defined as "residual dissatisfaction" (Andreasen, 1988, p. 687).

When dissatisfied consumers decide to complain, they are providing companies a second opportunity. Only when customers, through direct complaint, are looking for redress, apology, and psychological benefits will it be possible to transform their dissatisfaction into "a second, post-complaining, level of satisfaction or "secondary satisfaction"'(Oliver, 1987,p. 218).

However, complaint management seems to have two sides: on the one hand, it is a good opportunity to attract former customers; on the other hand, poor complaint management procedures can drive customers away forever. An interesting and challenging management of complaints, the company can understand the ans wers given and repurchase behavior in the future, but how the dissatisfied consumers perceived the satisfied or not, therefore, repurchase intention aware, to be completely unknown. Once customers have complained about a product or service and complaint management has been satisfactory, their behavior and attitude can change. Customers can decide to patronize the product or reuse the service provider. 


\subsection{Conceptual Model}

According to Tax and Brown (1998), around 10\% of dissatisfied customers actually lodge a formal complaint; the majority "are dissatisfied with the way companies resolve their complaints". The present study uses the model formulated by Day and Landon (1977). They presented a two-level hierarchical classification of consumer actions under dissatisfaction. The first level is divided into taking some actions and taking no action, and the second level separates public from private actions. Public actions comprise seeking redress directly from the seller, complaining to public or private agencies, such as a consumer organization, or taking legal actions. Typical private actions include boycotting the seller or manufacturer and warning friends and relatives (see Figure 2). Their conceptualization delineates circumstances leading to consumer dissatisfaction, a broad typology of complaint behavior, factors influencing complaint behavior and a preliminary decision model of complaint behavior.

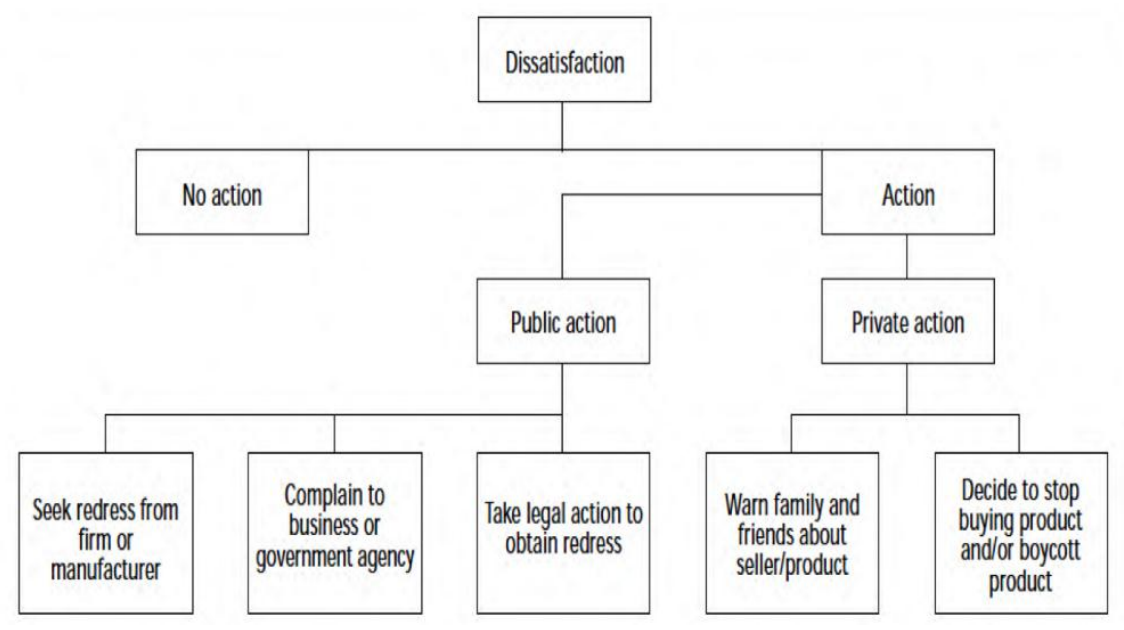

Figure 2. Taxonomy of Customer Complaint Behavior

Source: Day \& London, 1977.

\section{Methodology}

In this study, purposive sampling was adopted in the in-depth interviews. This method refers to the selection of units based on personal judgment rather than randomization (Sara, 2009). Purposive sampling aims to maximize the depth and richness of the data to address the research question (Kuzel, 1999; Dicicco-Bloom and Crabtree, 2006). An in-depth interview provides rich and in-depth information on experiences on the issue (Dicicco-Bloom and Crabtree, 2006). Purposive sampling also ensures that different characteristics of interviewees are included in the research (Sara, 2009) to provide a wide range of information for analysis.

In grounded theory studies, 25 to 30 participants interviewed in-depth is the minimum sample size required to reach saturation and redundancy (Dworkin, 2012). Using a small sample size ensures that the research is rich in constituencies and represents diversity (Ritchie and Lewis, 2003). We conducted interviews on 20 participants who met the following criteria.

A qualitative in-depth interview approach was to investigate customer complaint behavior toward low-cost carriers in Macau. The purpose of the in-depth interviews was to explore the experience of interviewers and the meaning they make out of that experience (Seidman, 1998; Elad \& Brashear, 2012). The approach helped reveal and solve unforeseen problems encountered in the industry (Jennings, 2001). The interview followed a semi-structured format with open-ended questions. The semi-structured interview is widely used because it is flexible, accessible, and intelligible. More importantly, interviews are capable of disclosing important and often hidden behaviors (Qu \& Dumay, 2011). Open-ended questions establish areas to be explored while allowing interviewers to take any direction (Elad \& Brashear, 2012). Interviews are a descriptive form of research designed to collect evidence to determine the "why" or "how" questions on single or multiple cases (Yin, 1994; Hyde, 2000). "Thick descriptions" are provided (Geertz, 1973; Sandy, 1979; Woodside \& Wilson, 2003; Elad \& Brashear, 2012) in investigating complaint behavior using the conceptual model. A pilot test was conducted in January 2017 to ensure that the interviewees understood the questions. Questions were reviewed and revised after the pilot test. Consent forms and emails were sent in early February 2017 to ensure that the respondents understood the context and rationale of the research. 
The interview questions are as follows:

\section{How do you file a complaint against low-cost carriers?}

2. What did you do when you felt dissatisfied with the products or service?

3. What do you expect to gain if you are not satisfied with the service or products of the low-cost carriers?

Content analysis was used in this study. According to Berg (2001), content analysis uses raw data read for the purpose of familiarity and coding preparation, followed by code frames. 'Codes' are tags or labels used to assign units of meaning of descriptive or inferential information compiled during a study (Miles \& Huberman, 1994). Content is coded at two levels: manifest (related to visible, surface content that provides ideas of a certain magnitude) and latent (related to the structural meaning conveyed by the data to seek underlying meaning). In the present study, latent content was assessed to examine the hidden meanings within the interview transcripts.

Data analysis follows several coding steps. In inductive coding, the researcher pays attention to what the interviewee or data convey and seeks insights into the information in the proper context and setting of the script. In contrast, deductive coding uses a top-down approach involving the application of explicit categories to identify and record data content, thereby avoiding prejudgment. The codes are compared with the findings and converted into coding frames, which are then used to code the data again and categorize them according to theme.

The coding results of the present study are displayed as different categories across the theme charts. MS Excel was used to present the data. The accounts separately displayed the results of the sorted data as collected from the interviewees.

Domain analysis was used to describe and analyze each theme separately. Findings at different levels were then synthesized and coding results at different levels compared to confirm the differences in opinions and suggestions.

A number of methodological issues are involved in transcribing audio tapes, such as Kvale (1996), for credibility and conformability (Devers and Frankel, 2000). Interviews are recorded through an audio recorder and note-taking. Raw data were then transcribed into Chinese and translated into English. Recording ensures that nothing will be missed during the interview. The researcher also asked interviewees to explain their ideas further to avoid confusing content, thereby avoiding any misunderstanding.

The true value and trustworthiness of research is based on credibility, transferability, dependability, and conformability (Lincoln and Guba, 1985; Shenton, 2003). These criteria were used to describe the validity and reliability of the present study.

Purposive sampling required the trustworthiness of the research conducted (Carlson, 2010). Therefore, some scholars used procedures, such as member checking (Creswell \& Miller; Merriam, 1998), to increase trustworthiness. Member checking is an opportunity for participants to approve particular aspects of the interpretation of the data they provided (Doyle, 2007; Merriam, 1998; Carlson, 2010), thereby increasing credibility and reducing the risk of misunderstanding (Curtin \& Fossey, 2007; Carlson, 2010).

\section{Results}

This study conducted in-depth interviews (ranging from 45 minutes to 1 hour) with 20 individual travelers. The interviews were conducted for four weeks from January to February 2017. The detailed profiles of the respondents are shown in Table 5. Half of the respondents are male (45\%), and half are female (55\%). Among the respondents, $70 \%$ are between 18 and 25 years old. In terms of education, $80 \%$ have a degree or have reached a higher education level. Most of the respondents' income was below HKD\$14,000 (75\%), and 100\% (20 out 20) have complained to low-cost carriers. The interviews were conducted smoothly at comfortable places, such as coffee shops, offices, and studios, which could encourage respondents' deep responses. Consent forms, interview invitation letters, key questions, and information fact sheets were sent to respondents via email before the interview to ensure they fully understand the objectives this study. The interviews were recorded and noted using a computer to guarantee the absence of misunderstanding. 
Table 1. Profile of Respondents

\begin{tabular}{|c|c|c|c|}
\hline Characteristics & & Frequency & Percentage \\
\hline \multirow[t]{2}{*}{ Gender } & Male & 9 & $45 \%$ \\
\hline & Female & 11 & $55 \%$ \\
\hline \multirow[t]{3}{*}{ Age } & 18 to 25 & 14 & $70 \%$ \\
\hline & 26 to 33 & 3 & $15 \%$ \\
\hline & 34 to 41 & 3 & $15 \%$ \\
\hline \multirow[t]{2}{*}{ Education Level } & $\begin{array}{l}\text { Certificate, diploma, or } \\
\text { higher diploma }\end{array}$ & 4 & $20 \%$ \\
\hline & Degree or above & 16 & $80 \%$ \\
\hline \multirow[t]{4}{*}{ Income Level } & $\$ 8000$ or under & 13 & $65 \%$ \\
\hline & $\$ 8001$ to 14,000 & 2 & $10 \%$ \\
\hline & $\$ 14,001$ to 20,000 & 2 & $10 \%$ \\
\hline & $\$ 20,001$ or above & 3 & $15 \%$ \\
\hline Complaint Experience & Yes & 20 & $100 \%$ \\
\hline with Low-cost Carriers & No & 0 & $0 \%$ \\
\hline
\end{tabular}

4.1 Macau Passengers'Perception toward Complaint to Low-cost Carriers

\subsubsection{Opinions on Complaints to Low-cost Carriers}

Most respondents believe that complaining is a rational phenomenon and a good way to express dissatisfaction if the service was not up to their standards. The respondents believe that a complaint must be followed by an improvement. However, some respondents did not expect much when they complained. They believe that not all low-cost carriers are willing to handle complaints. One respondent believes that complaining about a firm's attitude is necessary to bring light to the unfair treatment. The respondent believes that most low-cost carriers' performances were as low as their price.

\subsubsection{Reason for Macau Passengers to Complain to Low-cost Carriers}

Based on Chan (2000), two important base reasons on which buyers evaluate competing airline offers are schedule and price. However, there are other secondary reasons, but important, quality of service aspects that a consumer may consider in their ultimate choice of an airline. Such aspects as safety, comfort of the seats, in-flight amenities (e.g. food and be verages), attitude of the ground and flight crew, financial stability of the airline, on-time performance of the flights, assurance that luggage bags arrive with the passengers, the perceived likelihood of being "bumped" from a flight, and frequent flyer programs may also be important evaluation criteria.

So the author concluded three main situations that lead passengers to complain.

The first situation is cabin tangible elements, which include 1) narrow seats and 2) aging equipment. Most low-cost carriers use single and small airplanes to operate their flights. Companies add the most seats possible to maximize profits, but extra seats occupying limited space has led passengers to have uncomfortable experiences, such as 3) noise, 4) dirty cabins, and 5) selling of products. Low-priced tickets decrease profits. Thus, low-cost carriers have started selling products, such as fragrances and make-up, to gain further profits. Such action disturbs most resting passengers, who want a quiet cabin environment.

The second and most common situation is flight delays or immediate cancellations. All passengers regardless of destination would be affected if a flight does not depart on time.

The last situation is customer service, which focuses mainly on 1) staff attitude, 2) unprofessionalism, and 3) low efficiency. The researcher summed up the main reasons for complaints as service quality. Brand Tronvoll (2008) stated that "the service process on staff is important and affect service quality." Thus, the service quality of the staff is an important point in a low-cost carrier's business.

\subsection{Passengers Complaint Responses Expressed to Low-cost Carriers}

All respondents stated that they have filed complaints. The number of passengers who took private actions were slightly higher than those who took public actions. Private actions implied less effort for consumers to complain (Broadbridge \& Marshall 1995). Therefore, passengers find it easy to take private action for complaints. Only two out of twenty respondents claimed they will not proceed with any private action because it was "not worth complaining about" and "not effective." Most respondents claimed they would proceed with the private action, such as 1) spread negative word-of-mouth, 2) boycott the low-cost carrier, and 3) utilize social media. The respondents had shown their aggression regarding the incidents by using the internal source to share the experience with friends and family. The aim of sharing the experience with family and friends was 1) to alert friends and family, 2) encourage friends and family not to take the airline, 3) seek support, and 4) express and 
project. Given the present technological advancement, some respondents claimed they will share their experiences with others using an external source, such as sharing their flying experiences in their social media accounts. Respondents draw support from others by posting the experience on the social media platforms, such as Wechat, Weibo, Facebook, Instagram, and Fora.

Over half of the respondents take public action when they feel dissatisfied. Public action includes 1) complaining to the staff, 2) complaining to the cabin purser, 3) filling in the complaint forms, 4) contacting the low-cost carrier, 5) emailing the official website, and 6) gathering people to complain together. The aims of taking public action are 1) reflection, 2) seeking economic incentives, 3) solving problems, and 4) seeking an apology.

However, 6 out of 20 respondents would not take any public action because it is 1) useless 2) time consuming, 3) embarrassing, 4) pleasant emotion, 5) troublesome, and 6) lack of awareness. Some important factors influence passengers not to take any public action. Most passengers want to keep a good mood during their trips. Most Chinese passengers think complaining to the staff or cabin pursers face-to-face would be embarrassing. Moreover, some passengers are unaware of their rights and do not know how to complain. Thus, all low-cost carrier employees should be aware that taking care of an airline is a collective behavior. Passengers who are unorganized in advance may encounter unfair treatment or service failure. Chinese passengers gather together may express dissatisfaction.

\subsection{Recommendations to Management on Devising Policies to Improve Complaint Handling and Service Recovery}

More than half of the respondents would choose to patronize a carrier depending on 1) price, 2) flight time, and 3) preference. A total of $15 \%$ of the interviewees ( 3 out of 20 ) would not patronize the same low-cost carrier because of lack of trust. The respondents' answers show that low-cost carriers have no completely loyal passengers. Most passengers who take low-cost carriers only consider the price.

A total of $30 \%$ of interviewees ( 6 out of 20 ) would patronize the same low-cost carrier because of 1 ) good reputation or 2) having no other choice. This kind of phenomenon, which marketers should focus on, is that some passengers chose to patronize the carrier again not because they are satisfied but because some aviation routes in Macau had been monopolized by one low-cost carrier. Passengers were more likely to change their choices if another low-cost carrier operates the same route.

\subsubsection{Providing Training to Staff}

The respondents exhibited strong expectations that the carrier would provide staff training. Staff members are required to display good attitude and manners when serving passengers. Thus, the management must provide consumer service training more than job training. Such as 1) The classification of passenger complaints into invalid complaints and effective complaints, according to the causes, nature and extent of the consequences of different, but also divided into general complaints and major complaints. 2) Practitioners should improve their inner self-restraint, do good details and enhance their sense of responsibility. Customer service training could help maintain the carrier's reputation and increase profit.

\subsubsection{Revising the Management Process}

Several respondents claimed that they would not take public action because it is time-consuming. The complaint process is time-consuming and ineffective. Managers take a long time to handle their complaint. Moreover, passengers do not receive immediate and reasonable feedback. Thus, low-cost carriers must provide training on handling complaints among the managers to enhance customer loyalty.

\subsubsection{On-time Performance}

Punctuality is important for airlines and their passengers. (Soomer, M. J., \& Franx, G. J., 2008). Respondents claimed that some low-cost carriers are not usually punctual. A flight delay or cancellation would affect the passengers' itineraries and waste passengers' time. Thus, low-cost carriers must ensure punctuality and provide a series of measures to address situations that cause delay.

\section{Significance of the Findings}

The following table displays "new findings" from the in-depth interviews. 
Table 2. New Findings

\begin{tabular}{ll}
\hline Loyalty issue & $\begin{array}{l}\text { Low-cost carriers have no absolutely loyal passengers and low price is the key factor to } \\
\text { attract passengers. }\end{array}$ \\
\hline Cultural variable & Chinese "Face culture" and collectivism culture (DeFranco, 2005) \\
& Chinese passengers feel embarrassed if they complain to the staff face-to-face. \\
& Chinese passengers set higher standards to service providers because they need to be \\
given "face." & \\
People gather to complain together "collectivism" (Hofstede, 1980)
\end{tabular}

\subsection{Loyalty Issue}

Rothenberger, Grewal, and Iyer (2008) mentioned that price is a concrete cue used by consumers to evaluate quality, value, and purchase intentions. Favorable price perceptions (e.g., fair prices and good value) are likely to enhance customer loyalty (i.e., the greater likelihood of recommending and reusing the service provider). Flight ticket prices in the low-cost carrier industry change frequently. Moreover, every low-cost carrier sets low ticket prices. Hence, the absolutely cheapest air company cannot be determined. Price is the usual factor leading passengers to choose a low-cost carrier. A low-cost carrier with an "attractive" price becomes competitive even when its service quality is good as the others. Therefore, low-cost carriers do not have absolutely loyal passengers. The key marketing strategies are to try their best to provide good service and set the ticket prices as low as possible.

\subsection{Cultural Variable}

DeFranco et al. (2005) found that customers with different cultural backgrounds have different preferences on what is important, how service should be delivered, and whether complaints should be raised if the expected standards are not achieved. Au, Law, and Buhalis (2010) stated that culture plays an important role in determining how customers expect services to be delivered and their complaint behavior. Hofstede (1980, p. 260) defined culture as the "collective programming of the mind which distinguishes one group of people from another." National cultures differ mainly along four dimensions of power distance, individualism versus collectiveness (I/C), masculinity versus femininity, and uncertainty avoidance. Ho (1980) found that the Chinese attach great importance to the face issue following the high power distance characteristics. Lee and Sparks (2007) discovered that in the Chinese culture, a person's aggressive behavior in public may result loss of face not only for the individual but also for their group members. Similarly, respondents in the present research would feel embarrassed if they complain to the staff face-to-face. The face culture also leads to Chinese passengers setting higher standards for the cabin staff because they need be given "face." Low individualism ranking may be attributed to the high le vel of emphasis on a collectivist society by the communist rule. Some respondents stated that they may gather people to complain together. Therefore, the Chinese complain by collectivism to achieve what they want or have higher bargaining power.

\subsection{No Action}

No action does not mean absence of dissatisfaction. Some respondents claimed that they feel dissatisfaction but do now know how to protect their rights properly. Thus, they do not complain. Most respondents know the low-cost carriers' product features. Thus, they do not expect as much as what they expect from full-service carriers. The passengers do not have expectations and thus have no complaints.

\subsection{New Framework of Consumer Complaint Behavior}

Gourdin (1988) categorized airline service quality in terms of three items: safety, timelines and price. Elliott and Roach (1993) proposed food and beverage, timely luggage transport, seat comfort, the check- in process, and in-flight service dimensions. Haynes (1994) used the processing of luggage, seat cleanliness, and the check-in process, the convenience of transit, timelines, and handing of customer complaints as the standards of service quality.

Table 3 shows the consumer complaint behavior. Low-cost passengers in Macau take private action, such as sharing the negative word-of-mouth with friends and family on social media platforms and boycotting low-cost carriers. Public action includes complaining to the staff and cabin purser, filling in the complaint form, contacting the low-cost carrier, contacting the carrier through the official website, and gathering people to complain together. 
Table 3. New Framework of Customer Complaint Behavior

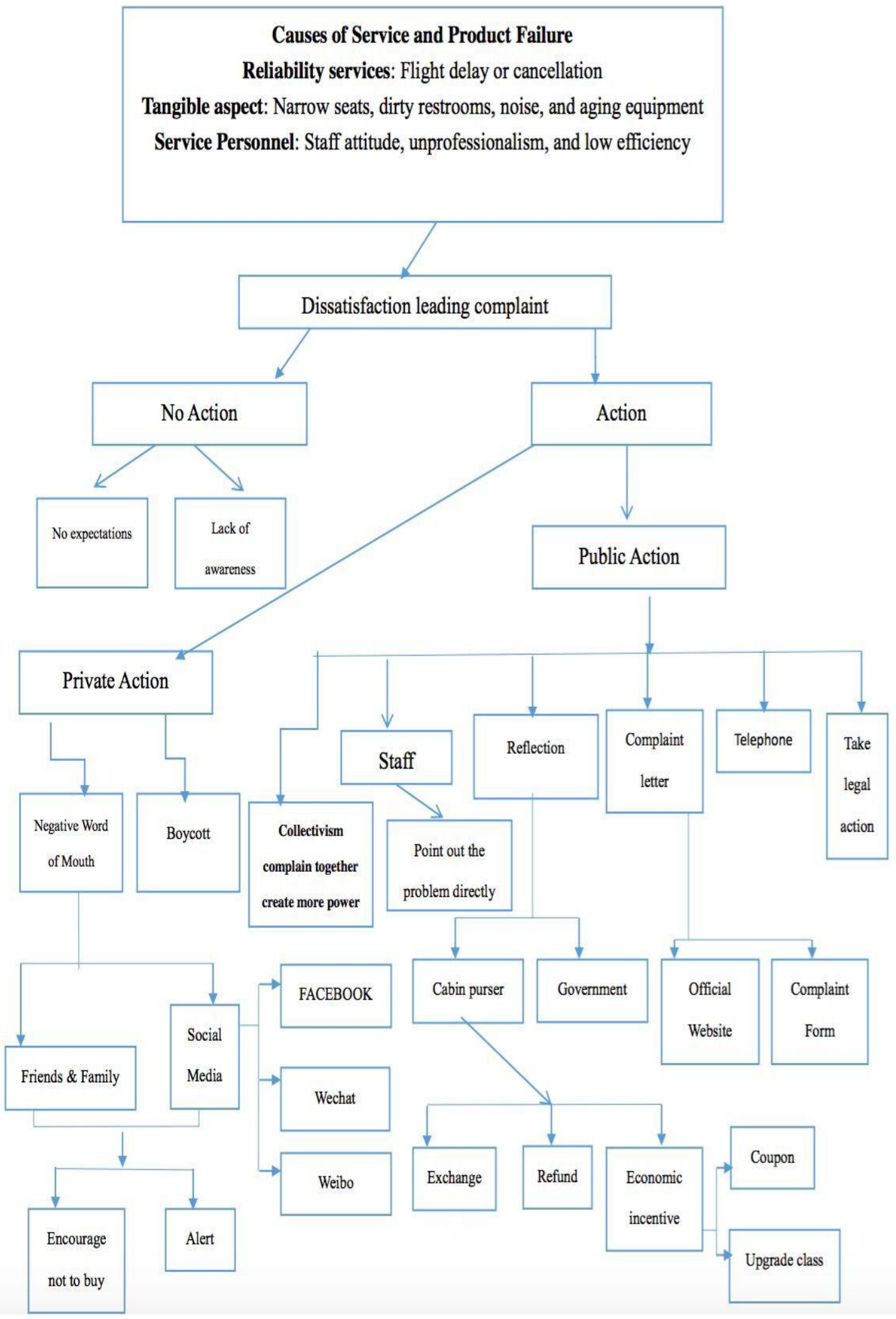

Resource: Adopted from Day \& London, 1977 


\section{Conclusion}

The airline industry is one of the most important industries that support Macau's economy and hospitality industry. Service providers in this industry should 1) improve and maintain service quality and 2) set the "most attractive" prices to compete with competitors. Moreover, service providers should satisfy customer expectations to generate sales profits and build positive word-of-mouth.

The result of the interviews reflected that cabin tangibles, service quality provided by the staff, and punctuality are the three main concerns of Macau passengers. The passengers take both private and public action to express dissatisfaction. The respondents would take public action by gathering people to complain together. They are concerned with the effectiveness and time consumption. Macau low-cost carriers should provide professional service quality to reach the expectation of customers, reduce their dissatisfaction, and improve their reputation and competitiveness. Therefore, the management and staff of low-cost carriers require further training to improve the companies'strategies and policies.

\subsection{Implicationsfor Marketers}

This research discovered that service quality is a critical concern among Macau passengers. Hence, airline management should focus more on the quality of service. Effective marketing strategies should be made considering the large number of alternatives in low-cost carriers. Therefore, the examination of service quality is essential to the industry.

Most respondents take both private and public action when they feel dissatisfied. Hence, the management should be more aware of these kinds of customers. Private action will not normally be brought to the attention of the business but will increase customer attrition. Therefore, service providers should be aware of such customers, obtain their feedback through a questionnaire, and engage them in conversations to gain information on their experience. Moreover, passengers of Macau's low-cost carriers would gather people to complain together, leading to a negative impact on low-cost carriers, which marketers should avoid.

The study also identified strong expectations of training among the staff and management. More training on consumer service is needed for the staff to maintain service quality. Training for the management could place more focus on handling complaints rather than job training. The management should also focus on flight punctuality. If the management handles complaints well, the carrier would increase the opportunity of repurchase. When complaints are resolved satisfactorily, there is a much higher chance that the customers involved will remain loyal. Complaint handing should be seen as a profit center and not a cost center. When a dissatisfied customer defects, the firm loses more than just the value of the next transaction.

\subsection{Implications for Academicians}

The study identified new findings on complaint behavior from Macau's low-cost carrier passengers. This study discovered new factors on complaints, which include loyalty and cultural issues. Previous studies have claimed that Chinese customers' aggressive behavior in public may result their losing face along with their group members. Therefore, Macau passengers would not complain to the staff face-to-face if they are dissatisfied. Moreover, price is a key factor considered by low-cost carrier passengers. A new conceptual model of CCB is created based on the responses of Macau passengers. Previous scholars have limited awareness of the culture differences with various aspects. The present study identifies the culture that leads to different attitudes as a result of different complaint behaviors. Therefore, this study adds value to the CCB framework.

\subsection{Limitations and Further Research}

This study emerged from the related literature, which included the use of secondary data analysis and in-depth interviews. However, this study has several limitations. First, it is limited in terms of sample size. The findings may not be representative of all Macau low-cost carrier passengers. The sample size was small with only 20 participants. Moreover, the research was limited to Macau passengers, and the results may be different from other countries. Therefore, the analysis was drawn with these restrictions in mind.

Future studies should utilize different approaches to collect data, such as the quantitative and qualitative approaches combined. Sample size should also be enhanced, and different education levels included to make the findings more representative and accurate. Furthermore, more in-depth interviews on the perception of complaint behavior, the action taken when consumers felt dissatisfied, or the improvement of low-cost carriers should also be conducted. 


\section{References}

Atalik, O. (2007). Customer complaints about airline service: A preliminary study of Turkish frequent flyers. Management Research News, 30(6), 409-419. https://doi.org/10.1108/01409170710751908

$\mathrm{Au}$, N., Law, R., \& Buhalis, D. (2010). The Impact of Culture on eComplaints: Evidence from Chinese Consumers in Hospitality Organizations. Information and Communication Technologies in Tourism 2010. Springer Vienna. https://doi.org/10.1007/978-3-211-99407-8_24

Bitner, M. J., Booms, B. H., \& Tetreault, M. S. (1990). The Ser vice Encounter: Diagnosing Favorable and Unfavorable Incidents. Journal of Marketing, 54(1), 71-84. https://doi.org/10.2307/1252174

Blodgett, J. G., Bakir, A., Saklani, A., Bachheti, M., \& Bhaskar, S. (2015). Customer Complaint Behavior: An Examination of Cultural VS. Situational Factors. Journal of Consumer Satisfaction, Dissatisfaction and Complaining Behavior, 28, 61-74.

Butelli, S. (2007). Consumer complaint behavior (CCB): A literature review. North Umbria University.

Chen, C. F. (2008). Investigating structural relationships between service quality, perceived value, satisfaction, and behavioral intentions for air passengers: evidence from Taiwan. Transportation Research Part A: Policy and Practice, 2(4), 709-717. https://doi.org/10.1016/j.tra.2008.01.007

Chenga, J. H., Chen, F. Y., \& Changc, Y. H. (2008). Airline relationship quality: An examination of Tai wanese passengers. Tourism Management, 29(3), 487-499. https://doi.org/10.1016/j.tourman.2007.05.015

Cronin, J. J. Jr., \& Gavin, L. F. (2010), he Implications of Third-Party Customer Complaining for Advertising Efforts. Journal of Advertising, 39(2), 21-33. https://doi.org/10.2753/JOA0091-3367390202

Davidow, M., \& Dacin, P. A. (1997). Understanding and influencing consumer complaint behavior: Improving organizational complaint management. Advances in Consumer Research, 24(1), 450-456.Retrieved from http://ezproxy.library.unlv.edu/login?url=http://search.ebscohost.com/login.aspx?direct=true $\& \mathrm{db}=$ buh\&AN=9706280225\&site $=$ bsi-live

Day, R. L., \& London, E. L. (1977). Toward a theory of consumer complaining behavior. In A. Woodside, J. Steht \& P. Bennet (Eds.), Consumer and industrial buying behavior. Amsterdam: North Holland Publishing company.

Day, R. L., Grabicke, K., Schaetzl, T., \& Staubach, F. (1981). The hidden agenda of consumer complaining. Journal of Retailing, 57(3).

Defranco, A., Wortman, J., Lam, T., \& Countryman, C. (2005). A Cross-cultural Comparison of Customer Complaint Behavior in Restaurants in Hotels. Asia Pacific Journal of Tourism Research, 10(2), 173-190. https://doi.org/10.1080/10941660500135969

Elad, G. G., \& Brashear, P. C. M. (2012).A structural guide to in-depth interviewing in business and industrial marketing research, Journal of Business \& Industrial Marketing, 27(7), 547-555 https://doi.org/10.1108/08858621211257310

Gilly, M. C., Stevenson, W. B., \& Yale, L. J. (1991).Dynamics of complaint management in the service organization, Journal of consumer affairs, 25(2), 295-322. https://doi.org/10.1111/j.1745-6606.1991.tb00007.x

Gupta, D. R., \& Sharma, P. (2015). A Study of Complaint Behavior Intentions of Airline Passengers.International Journal of Hospitality \& Tourism Systems, 8(2), 23-31. https://doi.org/10.21863/ijhts/2015.8.2.012

Harris, K. L., Lionel, T., \& Jacqueline, A. W. (2013). Justice for Consumers Complaining Online or Offline: Exploring Procedural, Distributive, and Interactional Justice, and the Issue of Anonymity, Journal of Consumer Satisfaction, Dissatisfaction, and Complaining Behavior, 26, 19-39.

Harrison, W. L. J. (2001). E-complaining: a content analysis of an Internet complaint forum. Journal of service marketing, 15(5), 397-412. https://doi.org/10.1108/EUM0000000005657

Hirschman, A. O. (1970).Exit, voice and loyalty: responses to decline in firms, organizations and states. Cambridge: Harvard University Press.

Ho, D. Y. F. (1980). Face and Stereotyped Notions about Chinese Face Behavior. Philippine. Journal of Psychology, 13, 20-33.

Hofstede, G. H. (1980). Culture's Consequences: International Differences in Work-related Values. Sage 
Publications, Beverly Hills, CA.

Hsieh, S. Y., Thomas, D., \& Rotem, A. (2005).The organizational response to patient complaints: a case study in Taiwan. International Journal of Health Care Quality Assurance, 18(4), 308-320. https://doi.org/10.1108/09526860510602578

Hung. C. W., \& Cheng, C. C. (2013). A hierarchical model of service quality in the airline industry. Journal of Hospitality and Tourism Management, 20, 13-22. https://doi.org/10.1016/j.jhtm.2013.05.001

Jacoby, J., \& Jaccard, J. (1981). The sources, meaning and validity of consumer complaint behavior: a psychological analysis. Journal of Retailing, 57(3), 4-23.

Jin, L. (2010). Determinants of customers' complaint intention. Nankai Business Review International, $1(1), 87$. https://doi.org/10.1108/20408741011032872

Kau, A. K., \& Loh, E. W. Y. (2006).The effects of service recovery on consumer satisfaction: a comparison between complainants and non-complainants. Journal of Service Marketing, 20(2), $101-111$. https://doi.org/10.1108/08876040610657039

Kulatunga, K. J., Amaratunga, R. D. G., \& Haigh, R. P. (2007). Researching construction client and innovation: methodological perspective, in: 7th International Postgraduate Conference in the Built and Human Environment. http://eprints.hud.ac.uk/22638/

Kvale, S. (1996). Interviews: an introduction to qualitative research interviewing. Thousand Oaks, CA: Sage

Lam, T., \& Tang, V. (2003). Recognizing Customer Complaint Behavior-The case of Hong Kong Hotel Restaurants. Journal of Travel \& Tourism Marketing, 14(1). http://dx.doi.org/10.1300/J073v14n01_05

Li, M. (2010). Exploration of Chinese consumer complaint behavior in the hospitality industry. Nevada University, Las Vegas. http://digitalscholarship.unlv.edu/thesesdissertations/653

Liu, R. R. \& McClure, P. (2001). Recognizing cross-cultural differences in consumer complaint behavior and intentions: an empirical examination, Journal of Consumer Marketing, 18(1), 54-75. https://doi.org/10.1108/07363760110365813

Min, G. K., Chung, H. L., \& Anna, S. M. (2014). Determinants of Customer Complaint Behavior in a Restaurant Context: The Role of Culture, Price Level, and Customer Loyalty. Journal of Hospitality Marketing \& Management, 23(8). http://dx.doi.org/10.1080/19368623.2014.896762

Oh, D. G. (2003). Complaining behavior of public library users in South Korea, Library and information science research, 25, 43-62. https://doi.org/10.1016/S0740-8188(02)00165-2

Oh, D. G. (2004). Complaining behavior of academic library users in South Korea, Journal of academic librarianship, 30(2), 136-144. https://doi.org/10.1016/j.acalib.2004.01.004

Oh, D. G. (2006). Complaining intentions and their relationships to complaining behavior of academic library users in South Korea, Library management, 27(3), 168-189. https://doi.org/10.1108/01435120610652914

Oliver, R. L. (1987). An investigation of the interrelationship between consumer (dis)satisfaction and complaint reports, Advances in consumer research, 14, 218-222. http://acrwebsite.org/volumes/6690/volumes/v14/NA-14

Özlem, A. (2007). Customer complaints about airline service: a preliminary study of Turkish frequent flyers. Management Research News, 30(6), 409-419. https://doi.org/10.1108/01409170710751908

Pels, E. (2008). Airline network competition: Full-service airlines, low-cost airlines and long-haul markets. Research in Transportation Economics, 24, 68-74. https://doi.org/10.1016/j.retrec.2009.01.009

Piercy, N. (1995). 'Customer satisfaction and the internal market: marketing our customers to our employees", Journal of Marketing Practice: Applied Marketing Science, 1(1), 22-44. https://doi.org/10.1108/EUM0000000003878

Plymire, J. (1991).Complaints as opportunities, Journal of consumer marketing, 8(2), 39-43. https://doi.org/10.1108/07363769110035009

Resnik, A., Gnauck, B., \& Aldrich, R. (1977). Corporate responsiveness to consumer complaints, in Day, R.L. (ed.) Consumer satisfaction, dissatisfaction and complaining behavior. Papers from a Marketing Research Symposium, School of business, Indiana University, Bloomington, April 20-22, 148-152.

Rothenberger, S., Grewal, D., \& Iyer, G. R. (2008). Understanding the role of complaint handling on consumer 
loyalty in service relationships. Journal of Relationship Marketing, 7(4), 359-376. https://doi.org/10.1080/15332660802516029

Sandy, Q., \& Qu, J. D. (2011). The qualitative research interview. Qualitative Research in Accounting \& Management, 8(3), 238-264. https://doi.org/10.1108/11766091111162070

Sanes, C. (1993). Complaints are hidden treasure, Journalfor quality and participation, 16(September), 78-82.

Sara, E. (2009). A methodological guide: Sampling methodology, Publication of International Labor Organization

Saunders, M., Lewis, P., \& Thornhill, A. (2003). Research methods for business students, 3rd, Pearson Education, England.

Seelos, L., \& Adamson, C. (1994). Redefining NHS complaint handling: the real challenge, Journal of Health Care Quality Assurance, 7(6), 26-31. https://doi.org/10.1108/09526869410067098

Singh, J. (1988). Consumer complaint intentions and behavior: Definitional and taxonomical issues. Journal of Marketing, 52, 93-107. http://www.jstor.org/stable/1251688

Singh, J. (1990). Voice, exit, and negative world-of-mouth behaviors: an investigation across three service categories. Journal of the Academy of Marketing Science, 18(1), 1-15. https://doi.org/10.1007/BF02729758

Soomer, M. J., \& Franx, G. J. (2008). Scheduling aircraft landings using airlines' preferences. European Journal of Operational Research, 190(1), 277-291. https://doi.org/10.1016/j.ejor.2007.06.017

Southwest Airline. (2014). Southwest Airlines. http://www.southwest.com.

Tax, S., \& Brown, S. (1998), "Recovering and learning from service failure", Management Review, 40(1), 75-88.

Tse, D. K., \& Peter, C. W. (1988). Models of Consumer Satisfaction Formation: An Extension, Journal of Marketing Research, 17(November), 460-469. https://doi.org/10.2307/3172652

Wang, X., Leou, C. H., \& Li, J. Y. (2016). A Study of Tourism Satisfaction and Destination Image for Leisure Travelers Who Use Macau Low-Cost Carriers. International Journal of Business Administration, 7(5). https://doi.org/10.5430/ijba.v7n5p1

Williams, G. (2001). Will Europe's charter carriers be replaced by "no frills" scheduled airlines. Journal of Air transport management, 7(5), 277-286. https://doi.org/10.1016/S0969-6997(01)00022-9

Yin, K. (2003). Case study research: design and methods, 3rd SAGE publications, Inc, California

Zhang, A., Hanaoka, S., Inamura, H., \& Ishikura, T. (2008). Low-cost carriers in Asia: Deregulation, regional liberalization and secondary airports. Research in Transportation Economics, 24, 36-50. https://doi.org/10.1016/j.retrec.2009.01.001

\section{Copyrights}

Copyright for this article is retained by the author(s), with first publication rights granted to the journal.

This is an open-access article distributed under the terms and conditions of the Creative Commons Attribution license (http://creativecommons.org/licenses/by/4.0/). 